\title{
IN SEARCH FOR AN INNOVATIVE BUSINESS MODEL OR HOW TO BE SUCCESSFUL IN THE NOWADAYS BUSINESS ENVIRONMENT
}

\author{
Brane Semolic \\ INOVA Consulting, \\ University of Maribor, Faculty of Logistics, Celje, Slovenia \\ Toolmakers Cluster of Slovenia \\ brane.semoli@siol.net
}

Classical organization of work does not support the nowadays needs of global market, competition and knowledge intensive economy anymore. The problem is how to maintain and develop the competitiveness at the global level. The article discusses global trends, new theoretical concepts, related problems and questions with some practical examples.

\section{INTRODUCTION}

The globalization and the fast technological changes require the organizations to develop competitiveness at the global level. This poses great problems, particularly to small and medium -sized enterprises (Case Study of Slovenia) having available limited resources, such as personnel, money, development - operational capacities or knowledge. Therefore, it is urgently necessary that they focus on selected business areas, where they are likely to develop and reach the global competitiveness. Other products or services required for performing their current or anticipated business activity can be procured outside their own organization on the global market. Generally speaking, the technologically developed companies from developed countries in most cases try to find production partners with cheap manpower for performing activities with lower added value. The organizations from technologically less developed regions try to find the business partners for development and transfer of new technologies into practice in their own companies. Of course, for the organizations from developed and less developed countries and regions there can be several reasons why they try to find business partners outside their own organization. Here, the organizations, wanting to develop by constant innovating in all areas of business activities, are concerned.

\section{THE GLOBAL MEGA TRENDS}

\subsection{The New Age Economy}

The fast technological development has brought about not only an expansive and fast development of new products and services but it also has caused that due to new technologies, particularly in the area of information science, telecommunications and

Scmolic, B., 2007, in IFIP International Federation for Information Processing, Volume 243, Establishing the Foundation of Collaborative Networks; cds. Camarinha-Matos, L., Afsarmanesh, H., Novais, P., Analide, C.; (Boston: Springer), pp. 111-122. 
transport the world has become smaller. Of course the world has not become smaller physically but the possibilities of communication and physical accessibility and the information control of the world have increased and cheapened and are still increasing and cheapening. One of the most important generic technologies is the INTERNET technology which has ensured the beginning of formation of a new economic order just like the steam machine technology had ensured the development of the industrial age.

Since a few recent decades in the area of global division of work we have been facing the changes of the conventional work division pattern based on the assumption that the economically developed countries develop and produce industrial products, whereas the less developed countries provide the raw materials and represent the market for these products. That process of changes started slowly to develop already immediately after the second world war. In the today's developed world economy we already face complex and intertwined situations, where the segmentation of the economic activities and their relocation all over the world take place. New, economically rapidly developing regions appear, which together with old centers of the developed countries form the new complex and intertwined whole of the global economy. The business associations supported by the modern information communication and transport technology are intensifying between the individual regions. A new work division based on knowledge - oriented economy is being established. The countries and regions having enough knowledge to develop the world competitive offer will enjoy successful economic development, whereas those not managing to do that will have to be satisfied with economic subordination.

\subsection{Searching for the new innovative business models}

Modern companies are permanently analyzing their business activities and the global market and are searching for business opportunities to improve the competitive capacities of their own company. New forms of network organization of the business activities of the companies appear which organize the individual business activities in the regions favorable from the business point of view with respect to the prices of manpower, special know-how as well as raw materials etc. Trans-national research, development and production networks are being formed and their formation and development are influenced by the extent of development of the business of the involved countries, regions, national and regional government rules and regulations, social and cultural conditions etc. The world becomes a more and more intertwined network consisting of a series of different trans-national networks and specialized economic entities, working in different parts of the world, included in it. Analyses of the geo-economic map show that the business activities can be distributed or concentrated but there is a tendency to organize such activities in the frame of geographically localized clusters. ${ }^{1}$ Porter defines a cluster as a geographically proximate group of companies and associated institutions in a particular field, linked by commonalities and complementarities. ${ }^{2}$ The industrial clusters can be formed as a result of the spontaneous development of a country of region or as a result of the implementation of the development policy of some country or region. Industrial clusters are often formed in close association with certain industrial branch or sector.

\footnotetext{
${ }^{1}$ Dicken P. Global Shift, 2003

${ }^{2}$ Porter M.: Cluster and new economics of competition, Harvard Busniess Review, 6, 1998
} 
Companies and organizations operating inside such cluster have the tendency towards closer business collaboration and association. The industrial clusters include companies, banks, educational and research institutions etc (Figure 1). Usually, such associating has a favorable influence on the growth of the innovation capacity of the economy involved and on the increase of its business success. Industrial clusters are aimed at increasing the global competitive capacity of the included part of economy in the selected area of its activities and, consequently, of the entire related geographic area.

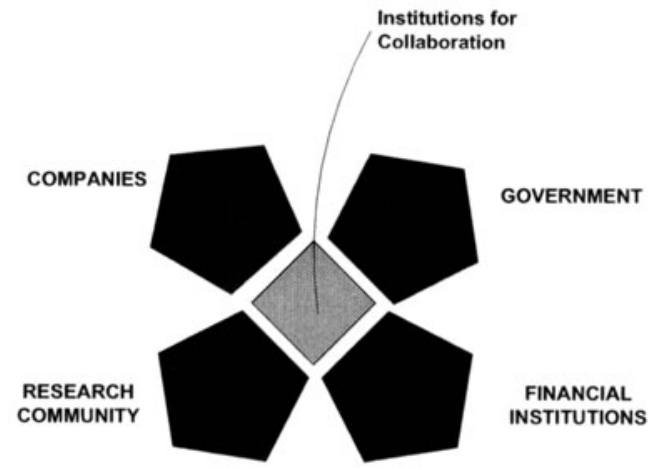

Figure 1: Partners of industrial cluster ${ }^{3}$

The business interest is one of the basic driving forces for formation and development of the industrial cluster. Formation and development of the individual segments of the cluster can be one or several companies wanting in this way to assure better conditions for developing own competitive capacity.

The nowadays companies need to search and maintain their key competence on the global level. This generate permanent problem to all companies worldwide. Especially for a small and medium sized companies (SME's) with limit resources. Clusters bring(s) SME's an opportunity to be more competitive on the global market. Such a small or medium sized company needs to see the cluster as an opportunity how to develop(e) a more innovative and efficient business model. Searching of the companies key competences and related optimization of the company's value chain by the insourcing and outsourcing become one of the most important strategic questions. The cooperation, collaboration, network organization and networking are "buzz" words of a new business concepts. The modern successful companies are not innovative on technologies only. They are permanently searching for innovations on all areas of their own business model. The typical elements of a company's business model are:
a. fundamental business assumption,
b. client selection,
c. specialization and scope of work,
d. differentiation,
e. stakeholders value creation,
f. procurement system,
g. production system,
h. go to market system,

${ }^{3}$ Solvell O. Lindquist G, Ketels K.: The Cluster Initiative Greenbook, Stockholm, 2003 
i. research and technology development (RTD) system,

j. project management system,

k. organization architecture design (OAD)

1. capital intensity,

m. knowledge management (KM) system

The managers need to permanently analyze (Figure 2) each parameter of their company business model and to find new ways how to be more effective and efficient according to the existing and foreseen technologies and market situation. The harmonized permanent development of all elements of company's business model can secure companies long term effiency and effectiveness.

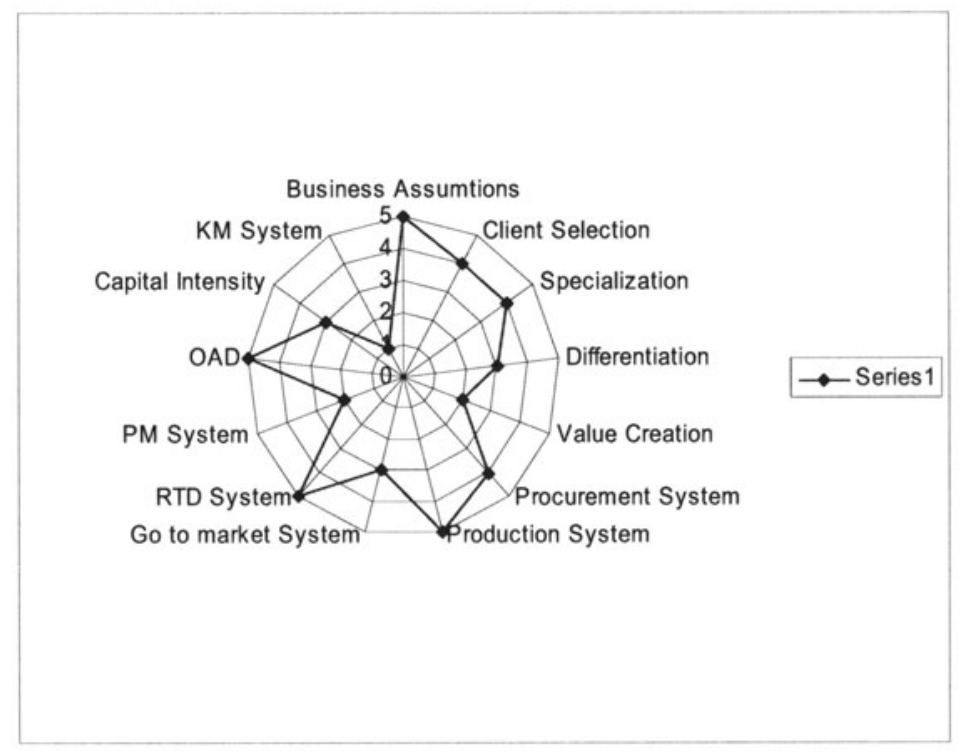

Figure 2: Example of the company's business model analysis

\subsection{Changes Obstacles}

The organizations must know how to take advantage of the changes brought about by the modern business environment otherwise they may cause much trouble. The extent of changes does not decrease, but it increases. Permanent changes and insecurity are the basic characteristics of the new economic order. In spite of that the changes, in most cases, are not implemented in practice as quickly as it would be desired. Why? Particularly because the execution of changes in own environment is often a difficult task. It is easier to let things happen. However, usually, things do not lead to targets which are so often optimistically written in various development documents and usually related to the international competition and the increase of the competitive capacity of own companies, sectors of economy, industries, regions, countries etc. There are many causes for such situation, including:

- lack of information,

- lack of required knowledge and qualification,

- non-innovative environment, 
- wrong beliefs and habits,

- lack of correct motivation,

- lack of entrepreneurial spirit,

- etc.

When analyzing the facts common to all these reasons we find that these are the problems which the modern management must be capable to solve. Here the management as activity and knowledge and the management as personnel performing the tasks are meant.

\section{NETWORK ORGANIZATIONS}

\subsection{Why need for a new business organization}

The organizational structure is defined as the sum of methods of how an organization breaks down its operation into the individual business activities and how it coordinates them. The organizational structure is a means by which the management realizes its business targets from the organizational point of view. The process of forming an organization is based on the analysis of the strategic targets and business environment of the organization. The findings so gained help to establish the organizational structure the adequacy of which must be continuously verified. In the present time of changes it may soon happen that the existing organization does no more meet the actual needs of the organization.

The conventional organization of the business activities was based on the high level of the organizational structure and support by the work rules and regulations defined in detail. Modern organization, which has to satisfy the needs of the unstable and fast changing environment is based on the loose management elements such as business targets, strategies and values.

The bases of the theory of companies' organization in the industrial age as set forth by Max Weber, Frederick W. Taylor, Henry Fayol and their contemporaries are based on the bureaucratic model of the organization and business activity structure. The principal characteristics of such organization are the hierarchy, relative impermeability and rigidity. Such a type of organization was adequate for the companies of the industrial age, since the business environment was relatively stable. Today we face the needs of fast development and permanent adaptability, therefore such organization is inadequate. Lately, various forms of network organization have appeared in answer to that problem.

\subsection{Enterprise project oriented network- flexible organization}

Taking into account that corporations operate within the dynamic environments requiring constant adjustment and development, it is possible to derive that the characteristics of sophisticated corporation are its dynamics, flexibility and quick adjustment, with an everlasting mixture of operative business processes of adjustment and development which require different approaches due to their mutual differences. In order to provide adequate management of business processes of the operation, adjustment and development, it is imperative to be completely familiar with the details of basic principles regarding particular business processes. Closer study of the 
fundamental properties of described types of business processes reveals that there are actually two types of business processes, namely:

- repetitive - continued business processes and

- non-repetitive - unique type business processes.

Continuous business processes are characteristic for the operative business processes featuring serial, mass production and other similar types of production, where we have to deal with repetitive business processes. From the content and quality aspect such processes remain relatively unchanged. Particular processes differ from each other only in regard to the volume of realization (quantitative dimension) of the already apprehended product/service. Within the network organization it is the matter of carrying out standardized and agreed productions and services, performed by the corporations, participants in the business network. Apart from the mentioned examples, such business processes may be identified also within the business areas (in any company regardless of the characteristics of its basic activity - operation) which provide the required infrastructure necessary for the performance of the basic business management activities of the company.

Unique business processes - projects, are present in all companies, whether within the performance of their principal line(s) of business (operative business processes) or within the realization of processes of development and adjustments of the company. These are considered as non-repetitive processes, aimed at realization of single objectives. Essentially this means innovations and innovation processes. In network organization such processes are performed within one corporation, within two of them or within the entire network of participating organizations.

Comparison of functional features and activities of the managerial process required to apprehend particular types of business processes, reveals that they considerably differ from each other. One of the basic differences indicates that in the management of continuous business processes these functions are related to the company resources, while the projects include also external resources, outside the corporation or business network of participating organizations. The term resources here denote all the capacities and other means at the disposition of the manager, employed to realize the set objectives mutually agreed upon. These objectives are situated within certain period of time (week, month, quarter, year), and they are monitored by analyzing the operation of a current period and comparing it with the preceding one. In case of project management one deals with planning, organization, guidance and controlling the resources, aimed at realization of single objectives within the specifically determined period of time. There are numerous differences between the management of continuous business processes and management of projects. Levine underlines the following features of project management, essential for the distinction between the general and project management, and related to the administration of continuous business processes:

- it is not obligatory to employ exclusively the potentials of the company - we may use the potentials of other corporations participating in the project;

- management of the project is a unique process, executed during the period of the performance of the project, which is precisely defined;

- it is necessary to realize precisely defined objectives, also of a single nature and

- Controlling of the project performance is structured according to a particular extent of work or a stage, required to be accomplished, and not according to periods of time as it is the case with the management of continuous activities. 
It is perhaps important to mention that the execution of projects usually requires greater "intellectual contribution" from participants, compared to the activities arising from the continuous regular business processes. It is equally important to indicate that the organization of work required for the execution of unique processes - projects is completely different from the organization of continuous business processes. In the first instance we are discussing different forms of project organization, with completely different characteristics and principles compared to the functional organization, which is otherwise usual in the execution of continuous business processes.

It is evident from the above that we are talking about particularities which demand different model of organization and execution of management functions. What we have in mind are above all different manner and approach to planning, organizing, administrating and controlling of business processes, aimed at realization of set objectives.

Basis for the creation of modern organization of a company are strategic business units (SBU), through which the company markets its products and services. Smaller permanent units may be created within the SBU (both within and outside the company) with the task of performing operative duties. For the adjustment and development requirements it is necessary to provide the required organizational background for the creation of temporary project groups, with the task of resolving unique problems.

At the strategic level there is the management of the company, which also has the permanent corporate organizational segment, consisting of the top management with the general administrative support, and temporary groups formed for the performance of projects in regard to the adjustments and development at the level of the whole company. The employed associates have the multifunctional responsibility, which means that they may at the same time be members of one permanent group and members of another project group.

In regard to the levels of authority such modern organization may be asymmetrical, in the sense of divergence, arising from the comparison of operative work within particular SBU.

A great contribution in providing conditions for reducing the number of managerial levels within a company and greater business integration into network organizations must be assigned to the tools of modern information technology which simplifies the communication and the performance of various forms of virtual organization. $^{4}$

By the definition of David Gould ${ }^{5}$ a virtual organization can be thought of as a way in which an organization uses information and communication technologies to replace or argument some aspect of the organization. People who are virtually organized primarily interact by electronic means.

Another very important element which must be taken into consideration in the implementation of modern, flexible, project-oriented organization of work within a company (Figure 3 ) is the cultural environment in which the company functions. What we have in mind is the reflection of general culture, displayed in form of

\footnotetext{
${ }^{4}$ Byrne J., Brand R., in Port O.: The Virtual Corporation, Business Weck, (8.2.93), New York, 1993 and Davidov W. H. in Malone M.S. : The Virtual Corporation, Harper-Collins, New York, 1993
} 
organizational culture of a company, and comprises a multitude of values, prerequisites and confidence which consciously or unconsciously influence the mode of conducting company business. If the organizational culture in the company is at low level, there is great possibility that only organizational changes may not yield worthwhile results. The outcome of an extensive survey, performed several years ago by Denison et al. has indicated that the difference between companies with good business results and those with bad ones in most cases depends upon the propensity of employers, their values and motivation - or in other words, upon the level of the organizational culture of people included in the process. The organizational culture is implicitly related to the strategies of the company, organization and organizational level of the company, and methods of managing the company. Harmony between the organizational culture in a corporation and adequate organization and management enables the company to function rationally and efficiently with minimal, merely formal inspections.

\section{TREND}

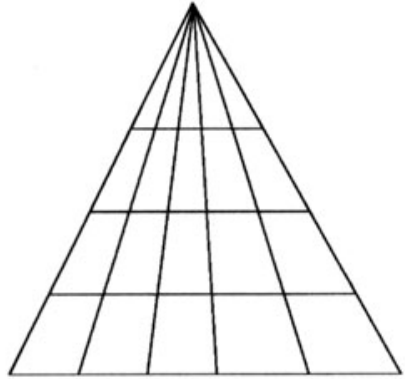

TRADITIONAL FUNCTIONAL ORGANIZATION

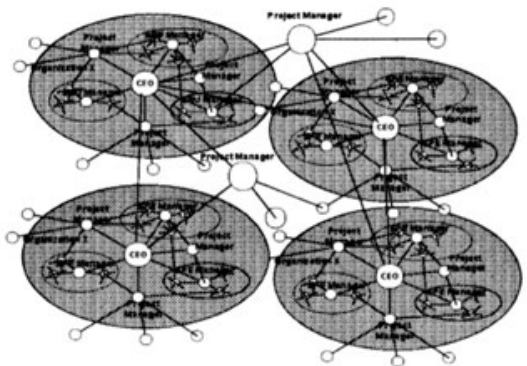

OPEN AND FLEXIBLE PROJECT ORIENTED NETWORK ORGANIZATION

Figure 3: Flexible project oriented network organization is much more effective in nowadays unstable business environment (Semolic B.: Project management, INOVA Consulting, 2005)

\section{CASE STUDY - EXPERIENCE FROM SLOVENIA (WWW.SLOVENIJA.SI)}

Slovenian economy is mostly presented and powered by the small and medium sized companies. The most presented industrial sectors are automotive, household appliances, machinery, electronics, pharmaceutical and service industries. The global competition and a fast technology development force companies to focus on their key competences and search for a regional and global outsource partners. This process has been started in the nineties and it has characteristics of exponent growth nowadays. To enhance and support the specialization, outsourcing and networking processes, Slovenian government started to support industry clusters and networking projects in the year 2000. This was made according to the results on extensive mapping research, which goal was looking for potential clusters. On the bas is of these results they made

${ }^{5}$ Gould D.: Virtual Organization, daveg@seanet.com, on INTERNET published paper, 2006 
open call for the first pilot cluster initiatives projects on the national level. In this stage the decision for the three pilot cluster project was taken. The proposed projects from the automotive, toolmakers and transport industry were awarded. The results of the first pilot projects followed to open call for a new cluster initiate projects support. This government initiative produced 16 new industrial clusters which included: ${ }^{6}$

- 335 small and medium sized companies,

- 72 big companies,

- 80 research and development institutes and

- 29 supporting organizations (for example: chamber of commerce, regional development agency etc.)

The partners in all clusters started more than 240 joint venture projects. The most common areas of co-operation are:

- Joint R\&D projects,

- Joint promotion and related projects

- Joint commercial projects,

- Joint infrastructure development,

- Education and training,

- Etc.

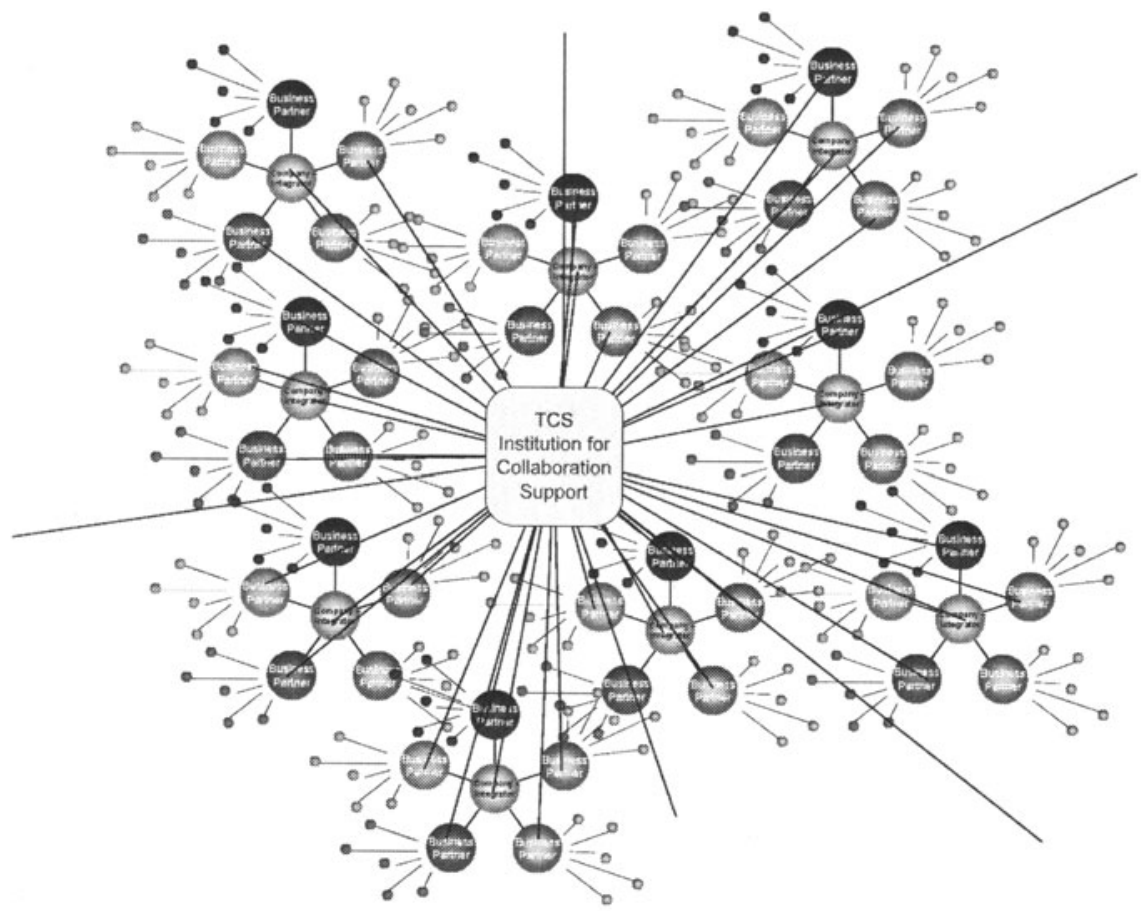

Figure 4: Illustration of Toolmakers Cluster of Slovenia

\footnotetext{
${ }^{6}$ M.Jaklic and Co.: Final Report, Faculty of Economics, University of Ljubljana, Ljubljana, 2004,
} 
Most of clusters established solid international links and co-operation with the similar or complementary clusters and networks. Figure 4 shows illustrative example of the regional Toolmakers Cluster of Slovenia (www.toolscluster.net).

The performed survey shows that companies see the clustering benefits in improvement of new technologies and know-how acquisition processes, improvement of companies international market visibility, possibility to perform bigger projects, better approach to the international supply/production chains and networks, enhance of company competitiveness etc.

The Figure 5 presents the illustration of the TCS current development project "TCS Laser Engineered Net Shaping (LENS) Living Laboratory (TCS Living Lab). The TCS Living Lab is the virtual dynamic network organization composed by the international group of R\&D organizations, product developers and end products and services users. The main purpose of this laboratory is to provide the global cutting edge laser know-how and services to included companies.

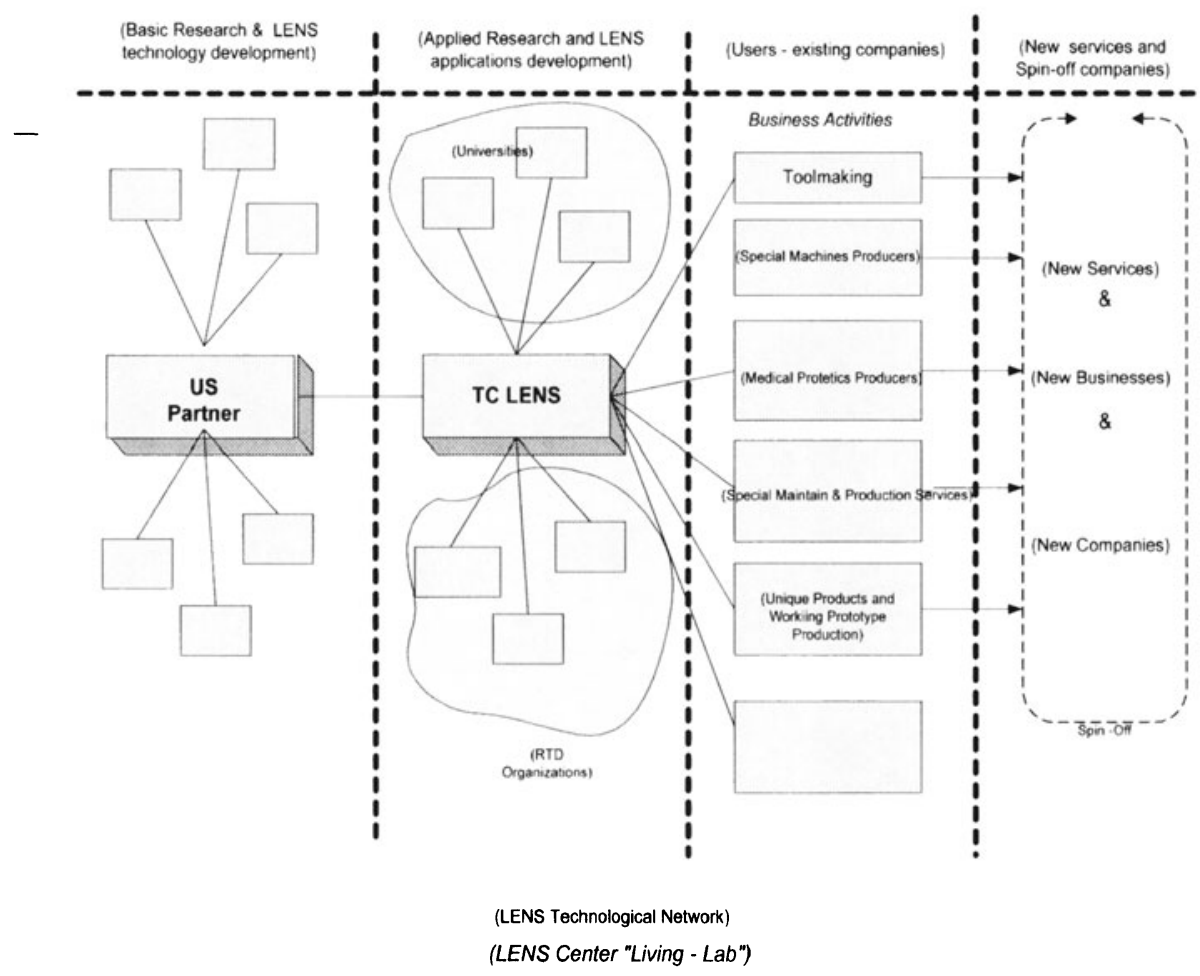

Figure 5: TCS LENS Living Lab 


\section{CONCLUSIONS}

The requirement for continual adjustment is imposed to organizations by the up-to-date environment. Companies are confronted with constantly increasing competitiveness. One of the elementary reasons of increased competitiveness of the business environment is globalization. Mainly the globalization processes impose to companies the requirement for analysis and re-estimation of their strategic orientations as well as modes and forms of operating and activity. The form of company organization is also ranged among areas necessitating radical transformation. We can assert that modern organizations have to face with the requirement for continual improvement of their mode or form of organization.

In globalization processes the SMEs (small and medium sized enterprises/ companies) are particularly exposed. And just for the said companies it is more and more difficult to achieve competitive advantages due to a great need for concentration of particular types of resources. Formation of network structures appears as a possible solution for SMEs at achievement of competitive capacity in the global business environment. Inter-corporate integration based on a very loose and temporary pooling of the necessary resources at achievement of a certain competitive advantage is the principal characteristic of network connections.

Clusters take a special position among network organizations. Integration and pooling of resources on the regional basis is a very spread form of achieving the competitive capacity at integration of SMEs. In Slovenia SMEs are predominant in the structure of organizations. Due to that the support to integration of SMEs at achieving of their global competitiveness is of significant importance for Slovenia. As it is evident from the presentation of experience in organization of clusters in Slovenia the establishment of network connections between SMEs represents a proper response to difficulties at their achieving of global competitiveness.

\section{REFERENCES}

[1] Drucker P.: Managing in the Next Society, St.Martin's Press, New York, 2002,

[2] Lynch, Richard, "Corporate Strategy, $2^{\text {nd }}$ Edition, Prentice Hall, London, 2000.

[3] Kaplan, R S, and Norton, D P, "The Strategy Focused Organization", Harvard Business School Press, 2001.

[4] Murray-Webster R and Thiry M, Gower Handbook of Project Management, 3rd Edition, Chapter 3, "Managing Programmes of Projects", Gower publishing, England, 2000, Ed. Rodney Turner.

[5] Steyn, Pieter G, "Managing Organizations Through Projects and Programmes: The Modern General Management Approach", Management Today, Vol 17, no 3, April 2001.

[6] Steyn, Pieter G, Proceedings of the First Joint IPMA and ICEC Congress, Llubjana, Slovenia, April 2006.

[7] Kotter, John P, "Leading Change”, Harvard Business School Press, 1996.

[8] Wyatt, W "Leadership: The Critical Key to Financial Success". Drake Business Review. Volume 1, Issue 1, 2003, pp 21-25.

[9] Dicken P, "Global Shift", Guilford Press, New York, 2003.

[10] Steyn P and Schmikl E, "Progamme Managing Organizational Performance and Improvement", unpublished textbook beta-version, Cranefield College of Project and Programme Management, South Africa.

[11] Semolic B.: A New Economy Trends and Organizational Changes, IPMA \& ICEC Expert Seminar, Portorož, 2002, 
[12] Semolic B.: The Project Management Organization - "The Quality Breakthrough", IPMA\&ICEC Expert Seminar, Bled 2003,

[13] Hoffman \& Co.: Internationales Projekt-management, DTV, Mainz, 2004. 